\title{
Communicating Geography with the Cloud
}

\author{
Durval Silva ${ }^{1}$ and Karl Donert ${ }^{2}$ \\ ${ }^{1}$ Elementary and Secondary School of Santa Maria-Beja, Portugal ·durval.silva@agrlbeja.pt \\ ${ }^{2}$ EUROGEO
}

Short paper

\begin{abstract}
Cloud computing is one of the hottest technological trends in education. According to Microsoft (2012), "With Cloud computing in education, you get powerful software and massive computing resources where and when you need them. [...] Cloud services can be used to combine on-demand computing and storage, familiar experience with on-demand scalability and online services for anywhere, anytime access to powerful web-based tools." This paper discusses the potentials that the cloud delivers for education, and introduces the "School on the Cloud" project.
\end{abstract}

\section{Introduction}

We are seeing an increased use of data in educational systems and a growing need to share data. Cloud-based developments enable downloads and uploads from student to student, from teacher to teacher, and first and foremost in and amongst schools, school boards and with official platforms. Education faces issues associated with communicating data confidentially, with security and fast access. These were perceived as the major issues identified by the state-of-the-art publication released in April 2014 by the School on the Cloud Key Activity 3 (ICT) European Network (DONERT 2014).

This abstract examines the aims of the School on the Cloud Project and considers the issues that those working in geospatial technologies are facing.

If on the one hand the proliferation of Cloud Computing in education is becoming a reality, it is important to have a critical attitude to its use, as well as constructive educational materials where the students can cooperate in acquiring knowledge through critical thinking and their commitment to acquire essential learning competences.

\section{Cloud Developments}

The emergence of the networked information economy has unleashed two powerful forces on education. On the one hand, easy access to high-speed networks is empowering individuals to access and use ICT. People can now discover and consume information resources and services globally. Furthermore, apps, combined with new social computing approaches, are inviting people to share the creation and ownership of, and learn from, information on emerging virtual environments. Secondly, ubiquitous access to high-speed networks along 
with open standards and content, and techniques for virtualisation is making it possible to leverage education through scale economies in unprecedented ways. What appears to be emerging is the ability for large-scale computing, high network bandwidth, huge data storage, protection, and many other related services to be easily available. So Cloud Computing represents a fundamental change in the way computing power is generated and distributed. It transforms the delivery of ICT tools and products into elastic, on demand services.

\section{The Potential for Education}

JOHNSON et al. (2012) commented on the noticeable increase in the number of education organisations investigating Cloud-based solutions. E-mail, calendaring, collaboration, videoconferencing, and even resource planning and learning management systems provided the potential for Cloud-based solutions. Organisations could migrate telephone systems, security systems, file storage, and almost every other aspect of ICT to the Cloud. Recent EU policy actions, aimed at removing barriers to Cloud Computing, were likely to have a huge impact on its adoption, development, and growth (BERRY \& REISMAN 2012).

Through the Cloud, real world, high specification, state-of-the-art software technologies can be accessed. These workplace tools can motivate and engage students, and prepare them for employment. However, selecting, implementing, and managing school-wide Cloud-based services and collaborative tools is challenging. Integrating possibilities with existing packages (for example presentations, Adobe, Google apps etc.) is an issue. Teachers, educators, and leaders need guidance and advice. In the present education environment, ICT support tends to be supported by local experts. Taking the complex ICT infrastructure to the Cloud should give these experts the time and space to cooperate with the teachers in exploring and developing better ways to use ICT in the class environment.

Many schools and educational organisations are considering migrating their activities to the Cloud as a result of the potential advantages it brings (MANSURI et al. 2014). Using the Cloud and apps in education lowers computer costs, makes them highly accessible and device independent. The Cloud also brings improved performance and cheaper software costs. Web-based apps are instantly and automatically updated, and there tend to be fewer problems with compatibility. The Cloud also offers large storage capacity with increased data reliability. Cloud computing is also said to be a comparatively data-safe computing environment. It encourages group collaboration and sharing through the ability to share and edit documents in real time between multiple users.

Cloud-based developments offer a new dynamic way to educate that aligns with how we think, share, learn, and collaborate outside of the classroom (ZWARTJES et al. 2014). The Cloud allows teachers and trainers to bring learning to life with dynamic, interactive, multimedia, learning activities. They can track individuals and groups, and assess how a topic or lesson has been received. Students are able to work in teams, collect shared data, and organize information - regardless of their time, day, or physical location. Content editing and sharing on the Cloud enables resources to be distributed in a range of formats. Through collaboration and presenting, Cloud-based learning helps pupils learn valuable workflow skills for the 21 st century workplace like teamwork. 
As learning becomes increasingly digital, online access becomes more important. Cloud Computing offers an opportunity to transform school pedagogy with services tailored to teachers' needs in individual classrooms. The Cloud can deliver services such as remote access to learning tools to school systems struggling with reductions in local and state funding in a cost effective manner. Students/pupils can access lesson activities on a laptop, tablet or phone from any location, and use the resources freely. At the same time, learners can ask and answer questions and share knowledge to help others. Through student preferences, the right content can be provided at the right time. Access to user analysis and data means that such a system can be adapted to ensure that it maximises efficiency and effectiveness, both for users and the education system. But most importantly, it helps young people access learning any-place any-how any time from any teacher with the right expertise.

Cloud-based educational content can be seen as an opportunity to ease the burden of teachers on knowledge transfer, but understanding the information in context, using it to solve problems (i.e. critical thinking), and building on it to create new knowledge are skills that will most often come through interactions students have with others and teachers/educators. These interactions may be face-to-face, online, or both, but the guidance of experts in a given field will continue to be a valuable part of the learning experience.

To many education technology leaders, the Cloud presents an opportunity to redefine the role ICT plays in implementing an education strategy. Because of its power to fundamentally change how learners cooperate and collaborate, the Cloud potentially changes the whole system of education. Therefore, Cloud Computing has the potential to change the whole educational system. The arrival of easily and regularly updatable eBooks will transform the textbook industry. Software companies like Adobe have been quick to create Cloud tools for teachers and learners to curate their own content. However, the changing technologies are producing a complex legal and regulatory environment, imposing responsibilities on providers and developers related to the collection, storage and processing of data.

\section{The School on the Cloud Project}

The School on Cloud Project is a three-year project that started in 2014. It addresses two key questions: i) how should education respond to the paradigm shift brought about by Cloud Computing, and ii) what will the impact be on education stakeholders and teachers, and what will it be like in the future? The Network consists of 57 European partners from 18 European countries: there are 21 Universities and teacher training departments, 9 NGOs, 8 schools, SMEs, research institutes, adult education and VET providers, a European professional association and a library (KOUTSOPOULOS \& KOTSANIS 2014).

To explore the potential of the Cloud in education, the School on Cloud network has established four working groups: 1. i-Manager: managing the transition from the ground to the Cloud: infrastructure, mentality, innovation and change, 2. i-Teacher: the role of the innovative teacher and teacher training; 3. i-Learner: integrating the Cloud in the learning experience, personalised learning, formal and informal education, special needs and 4. iFutures: developing visions on open education, interactivity, impact and communicating the Cloud. 
The goal of i-Manager is to identify and share technological, social, economic, cultural and other experiences in different educational contexts, by examining aspects of educational leadership, management, and organizational change in an era of Cloud-based developments. In order to accomplish that, it will examine aspects of leadership and management, essential if and when educational organizations decide to implement Cloud-based technologies. As a result, the group objective will be to produce a "Cloud-based Technologies Map" that will allow those involved in leading Cloud developments to consider different parameters in order to transfer good practice to their own circumstances.

i-Teacher explores the impact of Cloud Computing on teachers and trainers in informal and formal educational environments and the resulting teaching processes. In order to accomplish this, participants will examine the impact of Cloud-based technologies on the role of teachers and trainers in education, by examining the use of Cloud technology and applications as a value-added component in education. That is, examine the barriers and key competences required, and provide practical and essential guidance for teachers and teacher educators

i-Learner deals with the opportunities provided by the Cloud-based technology in personalising learning experiences "at any time, any place by any one". It seeks to understand how to exploit the opportunities resulting from both formal and informal learning situations using the new technologies. In order to accomplish that, participants will examine the impact of Cloud-based technologies on personalized learning.

i-Futures uses future tools, methods, and opportunities to build possible future scenarios for Education on the Cloud.

\section{Cloud Computing and Geospatial Education}

The Cloud has brought the power of Digital Earth computing platforms into the classroom, as data, tools, and apps have become available to educators. The many advances in terms of functionality, user interface, and system architecture allow geo-media to be served at a massive scale (LAMBRINOS \& ASIKLARI 2014). The potential of these technologies is now so powerful that its advances have led to a massive increase in the number of open access geospatial tools, interactive maps and applications. Geo-media is available for anyone to download and share. However, with such a plethora of resources emerging, most educators are finding it too challenging to keep pace with the changes taking place (DE MIGUEL \& DONERT 2014).

Cloud computing implies that interactive virtual perspectives of our planet are commonplace in terms of both its systems and forms; however, the possibility of scenario building and future perspectives, like urban planning, have not yet regularly been utilised in geospatial education despite the work of futurists like HICKS (2013) and participatory projects like GEOKOM-PEP (VOGLER \& HENNIG 2014). Creating innovative learning environments to integrate urban planning for the needs of future generations in schools is an important challenge, where youngsters can build realistic, short and long-term future scenarios for their local environment. 


\section{Conclusion}

Cloud-based approaches provide a dynamic way to educate, by implementing high specification, state-of-the-art technologies with real-time open access data. These Digital Earth learning environments can be used to motivate and engage students, and help to prepare them for employment. Learning is brought to life with dynamic, interactive, multimedia activities. Students, in all sectors of education (school, university, vocational, adult) are able to work in teams, collect shared data, organize and present information - regardless of the time, day, or physical location. Students thus learn valuable workflow skills for the $21 \mathrm{st}$ century workplace, but also teamwork through collaborating and presenting. Geospatial technologies are at the forefront of these developments, and have been at the core of School on the Cloud Project developments.

\section{References}

Berry, R. \& ReISMAN, M. (2012), Policy challenges of cross-border cloud computing. Journal of International Commerce and Economics, 4 (2), 1-38.

De Miguel. R. \& DonerT, K. (Eds.) (2014), Innovative Learning Geography in Europe: new challenges for the 21st Century. Cambridge Scholars Publishing, Newcastle.

DONERT, K. (2014), Education on the Cloud: state of the art survey. http://www.slideshare.net/TheSoFGr/soc-state-oftheart (31/3/2015).

HiCKS, D. (2013), Developing a futures perspective in the classroom. A Student's Guide to Education Studies, 133-145.

Johnson, L., ADAms, S. \& CuMmins, M. (2012), Technology Outlook for Australian Tertiary Education 2012-2017: An NMC Horizon Report Regional Analysis. New Media Consortium, Australia.

Koutsopoulos, K. C. \& Kotsanis, Y. C. (2014), School on Cloud: Towards a paradigm shift. Themes in Science and Technology Education, 7 (1), 47-62.

LAMBrinOS, N. \& ASIKLARI, F. (2014), The Introduction of GIS and GPS through local History Teaching in Primary School. European Journal of Geography, 5 (1), 32-47.

MANSURI, A. M., Verma, M. \& LAXKAR, P. (2014), Benefit of Cloud Computing for Educational Institutions and Online Marketing. Information Security and Computer Fraud, $2(1), 5-9$.

MicrosofT (2012), Cloud Computing in Education: http://sppilotco1.microsoft.com/education/en-us/solutions/Pages/cloud_computing.aspx $(31 / 3 / 2015)$.

VoGleR, R. \& HENNIG, S. (2014), Using geomedia for collaborative learning environments: the example of participatory spatial planning. In: JEKEL, T., SANCHEZ, E., GRYL, I., JounEAU-SiON, C. \& LYON, J. (Eds.), Learning and Teaching with Geomedia. Newcastle, 187-199.

Zwartjes, L., Papoutsis, P., Donert, K., Koutsopoulos, K. \& De Cupere, S. (2014), School on the Cloud: Connecting Education to the Cloud for Digital Citizenship. In Conference proceedings. The future of education (p. 253). libreriauniversitaria. it Edizioni. 